\title{
Oscillatory Reinstatement Enhances Declarative Memory
}

\author{
(1)Amir-Homayoun Javadi, ${ }^{1,2}$ James C. Glen, ${ }^{2}$ Sara Halkiopoulos, ${ }^{2}$ Mei Schulz, ${ }^{2}$ and Hugo J. Spiers ${ }^{2}$ \\ ${ }^{1}$ School of Psychology, Keynes College, University of Kent, Canterbury CT2 7NP, United Kingdom, and ${ }^{2}$ Institute of Behavioural Neuroscience, Department \\ of Experimental Psychology, University College London, London WC1H 0AP, United Kingdom
}

Declarative memory recall is thought to involve the reinstatement of neural activity patterns that occurred previously during encoding. Consistent with this view, greater similarity between patterns of activity recorded during encoding and retrieval has been found to predict better memory performance in a number of studies. Recent models have argued that neural oscillations may be crucial to reinstatement for successful memory retrieval. However, to date, no causal evidence has been provided to support this theory, nor has the impact of oscillatory electrical brain stimulation during encoding and retrieval been assessed. To explore this we used transcranial alternating current stimulation over the left dorsolateral prefrontal cortex of human participants $[n=70,45$ females; age mean $(\mathrm{SD})=22.12(2.16)]$ during a declarative memory task. Participants received either the same frequency during encoding and retrieval $(60-60 \mathrm{or} 90-90 \mathrm{~Hz})$ or different frequencies $(60-90$ or $90-60 \mathrm{~Hz}$ ). When frequencies matched there was a significant memory improvement (at both 60 and $90 \mathrm{~Hz}$ ) relative to sham stimulation. No improvement occurred when frequencies mismatched. Our results provide support for the role of oscillatory reinstatement in memory retrieval.

Key words: context; dorsolateral prefrontal cortex (DLPFC); memory; oscillation; reinstatement; transcranial alternating current stimulation (tACS)

\section{Significance Statement}

Recent neurobiological models of memory have argued that large-scale neural oscillations are reinstated to support successful memory retrieval. Here we used transcranial alternating current stimulation (tACS) to test these models. tACS has recently been shown to induce neural oscillations at the frequency stimulated. We stimulated over the left dorsolateral prefrontal cortex during a declarative memory task involving learning a set of words. We found that tACS applied at the same frequency during encoding and retrieval enhances memory. We also find no difference between the two applied frequencies. Thus our results are consistent with the proposal that reinstatement of neural oscillations during retrieval supports successful memory retrieval.

\section{Introduction}

Declarative memory recall is thought to involve the reinstatement of neural activity patterns that occurred previously during encoding (Norman and O'Reilly, 2003; Teyler and Rudy, 2007). In agreement with this model, greater similarity between patterns of activity recorded during encoding and retrieval tends to pre-

Received Jan. 28, 2017; revised July 19, 2017; accepted July 27, 2017.

Author contributions: A.-H.J. and H.J.S. designed research; A.-H.J., J.C.G., S.H., and M.S. performed research; A.-H.J. and H.J.S. analyzed data; A.-H.J., J.C.G., S.H., M.S., and H.J.S. wrote the paper.

This work was supported by the Wellcome Trust (Grant 094850/Z/10/Z) and James S. McDonnell Foundation to H.J.S. We thank Neil Garrett and Dharshan Kumaran for comments on the paper.

The authors declare no competing financial interests.

Correspondence should be addressed to either of the following: Dr. Amir-Homayoun Javadi, School of Psychology, Keynes College, University of Kent, Canterbury CT2 7NP, UK, E-mail: a.h.javadi@gmail.com; or Hugo Spiers, Institute of Behavioural Neuroscience, UCL Department of Experimental Psychology, 26 Bedford Way, London WC1H OAP, UK, E-mail: h.spiers@ucl.ac.uk.

DOI:10.1523/JNEUROSCI.0265-17.2017 Copyright $\odot 2017$ Javadi et al.

This is an open-access article distributed under the terms of the Creative Commons Attribution License Creative Commons Attribution 4.0 International, which permits unrestricted use, distribution and reproduction in any medium provided that the original work is properly attributed. dict better memory performance (Polyn et al., 2005; Johnson et al., 2009; Gordon et al., 2014). Recent models, drawing on new findings (Sederberg et al., 2007a; Wimber et al., 2012), have argued that neural oscillations may be crucial to reinstatement (Watrous and Ekstrom, 2014). However, to date, no causal evidence has been provided to support this theory, nor has the impact of oscillatory electrical brain stimulation during encoding and retrieval been assessed.

We now report causal evidence in support of the oscillatory reinstatement hypothesis. We took advantage of the potential capacity of transcranial alternating current stimulation (tACS) to entrain oscillations (Zaehle et al., 2010; Helfrich et al., 2014a). Gamma and theta oscillations have been shown to have a mechanistic role in memory formation (Sederberg et al., 2003, 2007b), linking memory formation to cellular mechanisms of learning (Jutras and Buffalo, 2010), and coordination of hippocampus with other brain areas (Fell et al., 2001; Colgin, 2011; for review see, Igarashi et al., 2014). We focused on gamma oscillations because tACS has been shown to enhance gamma oscillations (Strüber et al., 2014; Helfrich et al., 2014b), whereas tACS at other 
lower frequencies has been shown to have mixed effects on oscillatory power (Veniero et al., 2015). Additionally, as compared with theta band which has a narrower frequency band $(4-7 \mathrm{~Hz})$, gamma band have a wide frequency range of $30-120 \mathrm{~Hz}$, which gave us the flexibility of selecting two frequencies that are separate enough (i.e., 60 and $90 \mathrm{~Hz}$ ). We applied tACS to the left dorsolateral prefrontal cortex (DLPFC) of participants during a declarative memory task. The left DLPFC was targeted due to past research showing successful modulation of declarative memory by electrical brain stimulation (Javadi and Walsh, 2012; Javadi et al., 2012; Manenti et al., 2013; Sandrini et al., 2014; Zwissler et al., 2014). Participants received either the same frequency during encoding and retrieval (congruent group) or different frequencies (incongruent group). In a separate session, one week apart, sham stimulation was applied during encoding and retrieval. The order of sham and stimulation sessions was counter balanced across participants. Memory accuracy in this session was used as the baseline to compare with memory accuracy in the active-stimulation session.

\section{Materials and Methods}

Participants. Seventy healthy native English speaking adults [45 females, age mean $(\mathrm{SD})=22.12(2.16)]$ took part in two experimental sessions. They were randomly assigned to one of four conditions based on the frequency of tACS administered during encoding and retrieval. Congruent groups were 60-60 $(n=17)$ and $90-90(n=18)$, and incongruent groups were $60-90(n=17)$ and $90-60(n=18)$. For example, $60-90$ indicates an incongruent condition with $60 \mathrm{~Hz}$ tACS during encoding and $90 \mathrm{~Hz}$ tACS during retrieval (Fig. 1d).

All participants were naive to the study, English first language speakers, and right-handed yielding a laterality quotient of at least +50 on the Edinburgh Handedness Inventor (Oldfield, 1971). All participants had normal or corrected-to-normal vision, and all were screened to exclude those with a history of neurologic trauma or psychiatric disorder. No participant was taking any centrally acting medications. All participants gave their written informed consent in accordance with the Declaration of Helsinki and the guidelines approved by the Ethical Committee of University College London.

Transcranial alternative current stimulation. tACS (neuroConn DC Brain Stimulator Plus, neruoCare) was administered via two $5 \times 7 \mathrm{~cm}^{2}$ saline-soaked surface sponge electrodes. One electrode was placed over the left DLPFC ( $\mathrm{F} 3$ according to the 10-20 international system for EEG electrode placement) and one electrode over the left wrist. The left DLPFC was stimulated because both functional neuroimaging and brain stimulation data indicate it plays a prominent role in memory processing of written words (Blumenfeld and Ranganath, 2006; Staresina and Davachi, 2006; Murray and Ranganath, 2007; Javadi and Walsh, 2012; Javadi et al., 2012; Javadi and Cheng, 2013; for reviews of prefrontal interactions in long-term memory, see Simons and Spiers, 2003; Blumenfeld and Ranganath, 2007).

tACS was delivered during both encoding and retrieval phases with 1.5 $\mathrm{mA}$ peak-to-peak amplitude and $1 \mathrm{~s}$ ramp up and down. Stimulation was delivered either at 60 or $90 \mathrm{~Hz}$. These specific gamma frequencies were chosen because they both fall in the high gamma range $(60-140 \mathrm{~Hz})$, they are not resonant harmonics of one another, and there is a reasonable separation between them. This ensured that when stimulating at one of these frequencies the effect on the other frequency was minimized.
In both encoding and retrieval phases of one session, participants were stimulated for $15 \mathrm{~min}$ or $16 \mathrm{~s}$ for active $(60-60,90-90,60-90$, and 90-60) and sham stimulation conditions, respectively.

Stimuli. A bank of 590 words was extracted from The MRC psycholinguistic database (Coltheart, 1981). Words with high valence or similar meanings were excluded. Given that participants were instructed to visualize the words, highly familiar and easily imaginable words were selected. The words were controlled for the number of letters [minimum $=3$, maximum $=8$, mean $(S D)=4.89(1.24)]$, number of syllables $[$ minimum $=1$, maximum $=2$, mean $(S D)=1.49(0.50)]$, printed familiarity [mean $(\mathrm{SD})=552.54(34.75)]$, concreteness [mean (SD) 580.60 (34.06)], and imaginability [mean $(\mathrm{SD})=581.73$ (33.20)]. For each participant, the words used differed on each day.

Procedure. Each participant took part in 2 experimental days: one active stimulation and one sham stimulation, 1 week apart. Active and sham stimulation days were counterbalanced across participants. Participants were told that they both days would follow the same procedure and task. Each day consisted of encoding and retrieval phases and a $1.5 \mathrm{~h}$ retention interval in which participants stayed in the laboratory. During this time they watched episodes of a TV series while refraining from alcohol, caffeine, and smoking (Fig. 1a). Participants were aware that they would be tested on their memory performance in the retrieval session.

Behavioral tasks began 5 min after the onset of stimulation. In the encoding phase 100 words were presented one at a time $(0.6 \mathrm{~s})$ followed by an exclamation mark presented for $4.4 \mathrm{~s}$ which was designated as the memorization period. Words were separated by a $1 \mathrm{~s}$ fixation cross (Fig. $1 b)$. During the retrieval phase, previously presented words were randomly interleaved with 100 new words and presented one at a time. Participants were asked to judge whether the presented word was old (studied during the encoding phase) or new (Fig. 1c). The retrieval session was self-paced, but participants were told to work as swiftly as they could without sacrificing accuracy.

Stimulus presentation and response recording was conducted using MATLAB v2013b (MathWorks) and the Psychophysics Toolbox v3 (Brainard, 1997). SPSS v21 (IBM Lead Technologies) was used to carry out statistical analysis on the data.

Control study. To investigate whether participants in the incongruent condition could discriminate between the two stimulation frequencies, we ran a control study. Eighteen participants [10 female, mean age $(\mathrm{SD})=23.42(3.18)]$ took part in this study. During a randomized sequence of stimulation episodes (either 60 or $90 \mathrm{~Hz}$ ), participants were asked to judge whether the stimulation was the "same" or "different" from the previous episode. Stimulation setup was similar to the main study, except it was delivered for only $30 \mathrm{~s}$, followed by a 2 min rest. This was repeated nine times resulting in eight responses (no judg- 
Table 1. Summary of the $2 \times 2$ ANOVA with frequency of the 1 st and 2 nd sessions ( 60 and $90 \mathrm{~Hz}$ ) as independent factors, and percentage accuracy difference (percentage accuracy for the active - sham stimulation condition) for the old words and new words (separate), and $d^{\prime}$ difference ( $d^{\prime}$ for the active - sham stimulation condition) as dependent factors

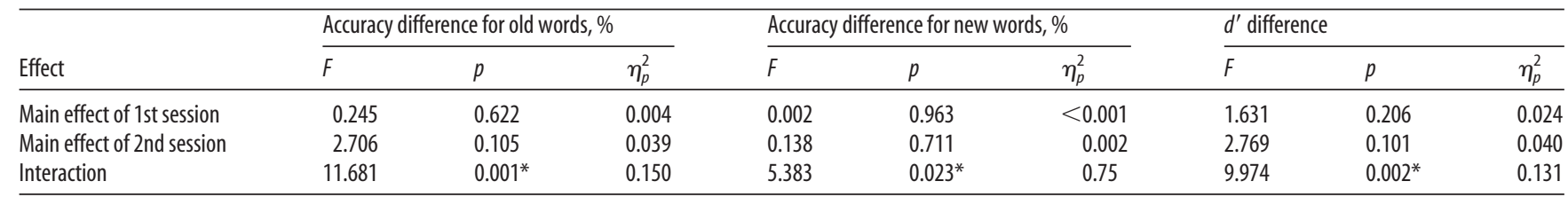

$F_{(1,70)}$ for all effects. ${ }^{*} p<0.05$.

a

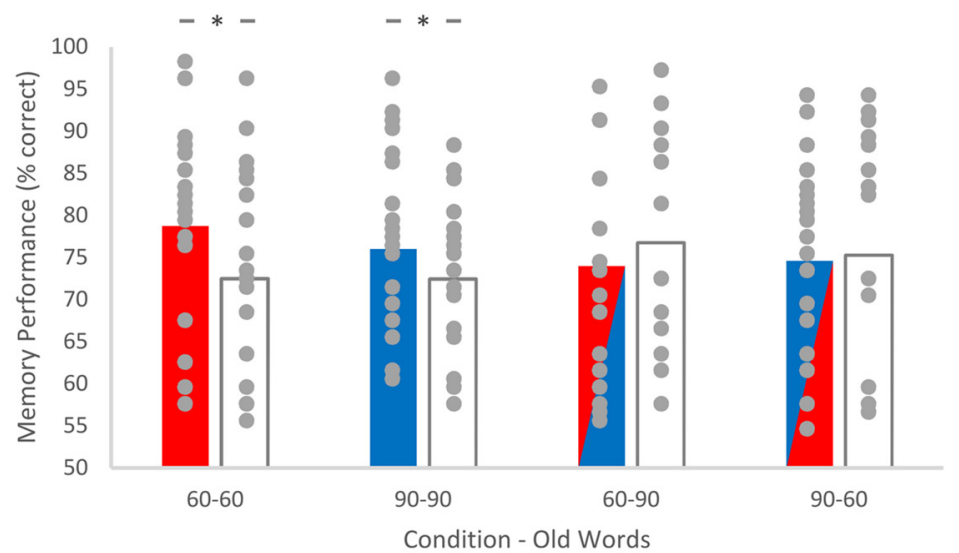

b

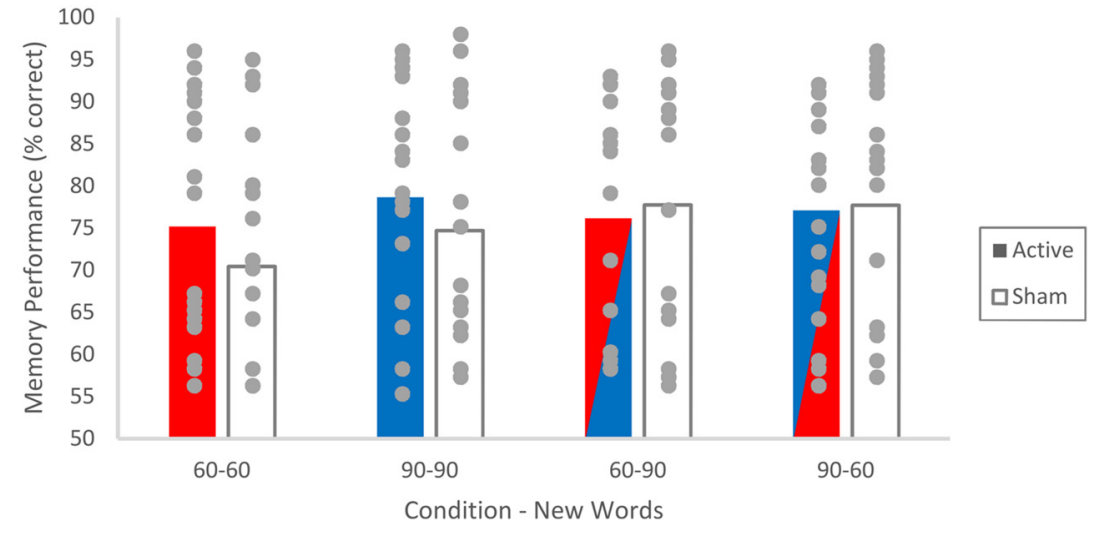

Figure 2. Performance (percentage correct for both old and new words) of the participants (within-subject design) in active and sham stimulation conditions for $(\boldsymbol{a})$ old and $(\boldsymbol{b})$ new words. Paired-sample $t$ tests comparing performance between active and sham stimulation conditions. Circles represent individual data points. ${ }^{*} p<0.05$.

ment was made after the first session as there was no comparison). See Figure $1 e$ for an example stimulation sequence.

Statistical data analysis. Response accuracy and reaction time were recorded for data analysis. Trials with response times $<200$ and $>5000 \mathrm{~ms}$ were removed from analysis $(0.128 \%$ of whole data).

We analyzed the data based on accurate responses for old and new words, as well as $d^{\prime}$. $d^{\prime}$ itself was calculated as $z$ (Hits) $-z$ (False Alarms). To determine whether left DLPFC tACS modulated memory performance we calculated the difference in performance between active and sham stimulation conditions ("percentage accuracy difference" for percentage accuracy and " $d$ ' difference" for $d^{\prime}$ ). We used performance difference because it provides measure of how much each individual was affected by the stimulation, thus accounting for variation between subjects in their sham session performance. Three $2 \times 2$ ANOVAs were conducted with frequency at the first and second sessions $(60$ and $90 \mathrm{~Hz})$ as independent factors, and difference in percentage accuracy for old and new words, and $d^{\prime}$ difference as dependent factors in each ANOVA. Post hoc one-sample $t$ tests were run to compare percentage accuracy difference and $d^{\prime}$ difference with zero in different groups. Effect sizes partial- $\eta$ squared for ANOVA and Cohen's $d$ are reported. Similar analyses were conducted on response times.
Data from the control study was analyzed using a one-sample $t$ test comparing the mean performance accuracy with chance level $50 \%$.

\section{Results}

In this study tACS was applied over the scalp above the left DLPFC of participants in a frequency-specific manner during a task involving encoding and delayed retrieval of written words. The ANOVAs looking at percentage accuracy difference for both old and new words, as well as $d^{\prime}$ difference, revealed nonsignificant main effects of frequency in the first and second sessions, but a significant interaction effect (Table 1). Post hoc one-sample $t$ tests on percentage accuracy difference showed significant differences for both of the congruent conditions for old words, and not for the conditions relating to new words (Fig. 2; Table 2). Similar tests on $d^{\prime}$ difference revealed that both congruent stimulation groups showed a significant enhancement in performance relative to sham stimulation, but no significant effect was present for either of the two incongruent groups (Table 3).

Although tACS above the left DLPFC appears to affect memory accuracy, no such effects were found for reaction times (RTs). Examining the differences between mean RTs in active and sham conditions for old and new words using two $2 \times 2$ ANOVAs revealed no significant main effects, nor significant interactions (all $p$ values $>0.200$ ).

Analysis of the control study showed that performance was not above chance level $\left(t_{(17)}=1.22, p=0.23\right)$. This nonsignificant difference shows that participants were not able to discriminate between the two stimulation protocols.

\section{Discussion}

In summary, relative to sham stimulation, memory performance (both when measured by percentage accuracy for old words and $d^{\prime}$ ) was significantly enhanced only when the same frequency was applied at encoding and retrieval (at both 60 and $90 \mathrm{~Hz}$ ), no significant effects were observed when the frequency of stimulation differed between encoding and retrieval. This effect was specific to performance, with no improvement in reaction times observed. Our analysis revealed that these effects were specifically present when individual subject's performance is accounted for by using our within-subjects measure of performance difference. 


\begin{tabular}{|c|c|c|c|c|c|c|}
\hline \multirow[b]{2}{*}{ Condition, Hz } & \multicolumn{3}{|c|}{$\begin{array}{l}\text { Accuracy difference for old } \\
\text { words, } \%\end{array}$} & \multicolumn{3}{|c|}{$\begin{array}{l}\text { Accuracy difference for new } \\
\text { words, \% }\end{array}$} \\
\hline & $t$ & $p$ & $d$ & $t$ & $p$ & $d$ \\
\hline $60-60 ; t_{(16)}$ & 2.815 & $0.012^{*}$ & 0.269 & 1.785 & 0.093 & 0.159 \\
\hline $90-90 ; t_{(17)}$ & 2.261 & $0.037^{*}$ & 0.210 & 1.515 & 0.148 & 0.011 \\
\hline $60-90 ; t_{(16)}$ & -1.737 & 0.102 & 0.173 & -0.858 & 0.404 & 0.048 \\
\hline $90-60 ; t_{(17)}$ & -0.411 & 0.686 & 0.108 & -0.284 & 0.779 & 0.191 \\
\hline
\end{tabular}

$d$, Cohen's $d$ effect size. ${ }^{*} p<0.05$.

Table 3. Summary of post hoc one-sample $t$ test on $d^{\prime}$

\begin{tabular}{lllrll}
\hline Condition, Hz & Active & Sham & \multicolumn{1}{l}{$t$} & $p$ & $d$ \\
\hline $60-60 ; t_{(16)}$ & $1.71(1.04)$ & $1.31(0.94)$ & 2.583 & $0.020^{*}$ & 0.403 \\
$90-90 ; t_{(17)}$ & $1.85(0.89)$ & $1.50(0.83)$ & 2.705 & $0.015^{*}$ & 0.406 \\
$60-90 ; t_{(16)}$ & $1.50(0.99)$ & $1.78(1.11)$ & -1.751 & 0.099 & 0.479 \\
$90-60 ; t_{(17)}$ & $1.80(0.96)$ & $1.66(0.97)$ & 0.957 & 0.352 & 0.043 \\
\hline
\end{tabular}

The raw values of $d^{\prime}$ are shown as mean (SD).

$d$, Cohen's $d$ effect size. ${ }^{*} p<0.05$.

Using the capacity of tACS to entrain oscillations in the cortex (Zaehle et al., 2010; Helfrich, Schneider et al., 2014) we test three hypotheses: (1) application of oscillatory brain stimulation during encoding and retrieval enhances memory, (2) memory performance may be enhanced by specific stimulation frequencies, and (3) the reinstatement of the same frequency is required across encoding and retrieval for memory enhancement. Our first hypothesis was motivated by the possibility that tACS provides a similar enhancing effect on memory as transcranial direct current stimulation (tDCS). This is based on evidence that both tDCS and tACS can enhance working memory (Fregni et al., 2005; Andrews et al., 2011; Jaušovec and Jaušovec, 2014) and that tDCS can enhance declarative memory (Jacobson et al., 2012; Javadi and Walsh, 2012; Javadi et al., 2012; Javadi and Cheng, 2013). Thus, it seems plausible that tACS, like tDCS, may also generally enhance declarative memory. Motivation for our second hypothesis comes from evidence that power increases in certain gamma frequency bands $(30+\mathrm{Hz})$ have consistently been associated with successful memory retrieval (Gruber et al., 2004; Osipova et al., 2006; Sederberg et al., 2007a; Hanslmayr and Staudigl, 2014; for review, see Düzel et al., 2010; Nyhus and Curran, 2010), suggesting that certain frequencies of tACS may be more beneficial than others. Our third hypothesis is based on recent models (Hanslmayr and Staudigl, 2014; Watrous and Ekstrom, 2014) that argue that frequency-specific reinstatement of oscillatory activity from encoding during retrieval serves accurate memory recall.

Our results help advance models of memory processing. Numerous models have argued that the successful retrieval of past experience involves a reinstatement of activity that previously occurred during encoding (Norman and O'Reilly, 2003; Teyler and Rudy, 2007). More recently several models have argued that neural oscillations are central to this reinstatement process (Watrous and Ekstrom, 2014; Watrous et al., 2015). Such models build on mounting evidence that memory retrieval success is related to the strength of the correlation between neural oscillations recorded during encoding and retrieval (Sederberget al., 2007a; Wimber et al., 2012). However, it has been noted that causal evidence for this process is lacking (Sederberg et al., 2007a; Watrous et al., 2015). Thus, our evidence that oscillatory brain stimulation (tACS) at the same frequency at encoding and re- trieval leads to an enhancement of memory provides important support for these theories. Neural recording studies showing oscillatory reinstatement demonstrate that the reinstatement can occur very rapidly after cueing (Wimber et al., 2012), leading to the suggestion that the reinstatement is part of the rapid retrieval process, rather than post-retrieval processing. In this view, the stimulation enhances memory by reinstating the encoding conditions in the network of brain areas responsible for the reactivation of the memory trace. This reinstatement may enhance processes such as pattern completion (Staresina et al., 2012, 2016; Tompary et al., 2016) where similar network level inputs are transmitted to regions reconstructing the pattern of activity laid down at encoding, such as is thought to occur in hippocampal area CA3 (Norman and O'Reilly, 2003; Neunuebel and Knierim, 2014; Rolls, 2016). However, it is also possible that oscillatory reinstatement aids memory performance by enhancing a post-retrieval process where the oscillations help mediate interactions between different brain areas (Watrous et al., 2013; Thakral et al., 2015). For example, a potential mechanism might be that after the memory trace is reactivated the reinstated oscillations from the time of encoding provide extra neural context (specific network patterns of activity) that improves the assessment of retrieved memory to determine veracity of the memory. Future work will be required to clarify such aspect of the models.

Our results showed that superior performance in the congruent stimulation condition as compared with incongruent stimulation condition was due to better recognition of old stimuli (Table 2). This suggests the enhancement may be more specific to retrieving the memory trace rather than enhancing post-retrieval processes that allow new items to be rejected (Javadi and Walsh, 2012; Manenti et al., 2013; Chua and Ahmed, 2016). Given evidence of two distinct but interacting functional systems for familiarity and novelty (Tulving et al., 1996; Viskontas et al., 2006; Yassa and Stark, 2008; Kafkas and Montaldi, 2014) another possibility is that the specific enhancement for "old" judgements is due to an upregulation in the familiarity system. It may be that targeting the DLPFC with our stimulation had this effect due to the involvement of prefrontal regions in supporting familiarity judgments (Tulving et al., 1996; Yassa and Stark, 2008; Kafkas and Montaldi, 2014). Further research separating novel, familiarity, and recollection would be useful to explore these possibilities.

Our results provide a novel addition to research into statedependent learning, which has predominantly been investigated via the application of drugs during encoding and retrieval (Goodwin et al., 1969; Petersen, 1979; Kelemen and Creeley, 2003). Such prior work has shown that matching physiological states during encoding and retrieval can enhance memory, but there has been little attempt to manipulate the specific neural mechanisms underlying state-dependent memory. By building on recent observations that tACS can entrain brain oscillations (Helfrich et al., 2014a), we were able to specifically test model predictions (Watrous and Ekstrom, 2014; Watrous et al., 2015) and the specificity of the entrainment. One possible outcome from our results would have been that the state-dependent induction of gamma oscillations is sufficient to enhance memory. However we did not find this, rather we found that a precise match in the exact gamma frequency used was required to induce our memory enhancement, as predicted by models (Watrous and Ekstrom, 2014). Our results cannot be explained by the subjective discrimination between the two stimulation frequencies, as our control study showed that participants were not able to judge whether two consecutively delivered stimulations are the same or 
different. This supports the contention that impact of tACS is due to alterations in brain oscillations rather than an awareness of being in different states.

Previous studies have shown memory enhancement after deep brain stimulation to the entorhinal cortex (Cheng and Anderson, 2012; Suthana et al., 2012), transcranial magnetic stimulation to scalp above the DLPFC (Turriziani et al., 2012) or parietal cortex (Wang et al., 2014), and tDCS to the scalp above DLPFC (Javadi and Walsh, 2012; Javadi and Cheng, 2013; for reviews, see Spiers and Bendor, 2014; Spiers et al., 2017). Here we extend such work to the relatively less studied application of tACS, and in contrast to the majority of electrical stimulation studies (Bestmann et al., 2015), we provide a test of a specific neural mechanism-oscillatory reinstatement. Although our stimulation protocol targeted the left DLPFC, it is important to note that the relatively wide spatial extent of tACS means that it may have had effected adjacent brain regions. In addition, DLPFC has many connections with both cortical and subcortical structures; therefore, although stimulation occurred here there may have been effects at remote sites. As such, caution must be taken when interpreting the specificity of our observed results to the left DLPFC. One useful extension of our findings is to the domain of memory consolidation, where a number of studies have begun to explore the impact of oscillatory brain stimulation during sleep (Marshall et al., 2006, 2011). In this context it is possible that reinstatement of the gamma frequencies used in our study may disrupt the endogenous slow-wave sleep period consolidation mechanisms leading to memory deficits and perhaps the introduction of previous waking experiences into the postsleep dream reports through the reactivation of memory traces.

\section{References}

Andrews SC, Hoy KE, Enticott PG, Daskalakis ZJ, Fitzgerald PB (2011) Improving working memory: the effect of combining cognitive activity and anodal transcranial direct current stimulation to the left dorsolateral prefrontal cortex. Brain Stimul 4:84-89. CrossRef Medline

Bestmann S, de Berker AO, Bonaiuto J (2015) Understanding the behavioural consequences of noninvasive brain stimulation. Trends Cogn Sci 19:13-20. CrossRef Medline

Blumenfeld RS, Ranganath C (2006) Dorsolateral prefrontal cortex promotes long-term memory formation through its role in working memory organization. J Neurosci 26:916-925. CrossRef Medline

Blumenfeld RS, Ranganath C (2007) Prefrontal cortex and long-term memory encoding: an integrative review of findings from neuropsychology and neuroimaging. Neuroscientist 13:280-291. CrossRef Medline

Brainard DH (1997) The psychophysics toolbox. Spat Vis 10:433-436. CrossRef Medline

Cheng JJ, Anderson WS (2012) Deep brain stimulation of entorhinal cortex shows early promise for enhancement of memory function. Neurosurgery 71:N24-25. CrossRef Medline

Chua EF, Ahmed R (2016) Electrical stimulation of the dorsolateral prefrontal cortex improves memory monitoring. Neuropsychologia 85:7479. CrossRef Medline

Colgin LL (2011) Oscillations and hippocampal-prefrontal synchrony. Curr Opin Neurobiol 21:467-474. CrossRef Medline

Coltheart M (1981) The MRC psycholinguistic database. Q J Exp Psychol 33:497-505. CrossRef

Düzel E, Penny WD, Burgess N (2010) Brain oscillations and memory. Curr Opin Neurobiol 20:143-149. CrossRef Medline

Fell J, Klaver P, Lehnertz K, Grunwald T, Schaller C, Elger CE, Fernández G (2001) Human memory formation is accompanied by rhinal-hippocampal coupling and decoupling. Nat Neurosci 4:1259-1264. CrossRef Medline

Fregni F, Boggio PS, Nitsche M, Bermpohl F, Antal A, Feredoes E, Marcolin MA, Rigonatti SP, Silva MT, Paulus W, Pascual-Leone (2005) Anodal transcranial direct current stimulation of prefrontal cortex enhances working memory. Exp Brain Res 166:23-30. CrossRef Medline

Goodwin DW, Powell B, Bremer D, Hoine H, Stern J (1969) Alcohol and recall: state-dependent effects in man. Science 163:1358-1360. CrossRef Medline

Gordon AM, Rissman J, Kiani R, Wagner AD (2014) Cortical reinstatement mediates the relationship between content-specific encoding activity and subsequent recollection decisions. Cereb Cortex 24:3350-3364. CrossRef Medline

Gruber T, Tsivilis D, Montaldi D, Müller MM (2004) Induced gamma band responses: an early marker of memory encoding and retrieval. Neuroreport 15:1837-1841. CrossRef Medline

Hanslmayr S, Staudigl T (2014) How brain oscillations form memories: a processing based perspective on oscillatory subsequent memory effects. Neuroimage 85:648-655. CrossRef Medline

Helfrich RF, Schneider TR, Rach S, Trautmann-Lengsfeld SA, Engel AK, Herrmann CS (2014) Entrainment of brain oscillations by transcranial alternating current stimulation. Curr Biol 24:333-339. CrossRef Medline

Helfrich RF, Knepper H, Nolte G, Strüber D, Rach S, Herrmann CS, Schneider TR, Engel AK (2014) Selective modulation of interhemispheric functional connectivity by HD-tACS shapes perception. PLoS Biol 12: e1002031. CrossRef Medline

Igarashi KM, Lu L, Colgin LL, Moser MB, Moser EI (2014) Coordination of entorhinal-hippocampal ensemble activity during associative learning. Nature 510:143-147. CrossRef Medline

Jacobson L, Goren N, Lavidor M, Levy DA (2012) Oppositional transcranial direct current stimulation (tDCS) of parietal substrates of attention during encoding modulates episodic memory. Brain Res 1439:66-72. CrossRef Medline

Jaušovec N, Jaušovec K (2014) Increasing working memory capacity with theta transcranial alternating current stimulation (tACS). Biol Psychol 96:42-47. CrossRef Medline

Javadi AH, Walsh V (2012) Transcranial direct current stimulation (tDCS) of the left dorsolateral prefrontal cortex modulates declarative memory. Brain Stimul 5:231-241. CrossRef Medline

Javadi AH, Cheng P, Walsh V (2012) Short duration transcranial direct current stimulation (tDCS) modulates verbal memory. Brain Stimul 5:468-474. CrossRef Medline

Javadi AH, Cheng P (2013) Transcranial direct current stimulation (tDCS) enhances reconsolidation of long-term memory. Brain Stimul 6:668 674. CrossRef Medline

Johnson JD, McDuff SG, Rugg MD, Norman KA (2009) Recollection, familiarity, and cortical reinstatement: a multivoxel pattern analysis. Neuron 63:697-708. CrossRef Medline

Jutras MJ, Buffalo EA (2010) Synchronous neural activity and memory formation. Curr Opin Neurobiol 20:150-155. CrossRef Medline

Kafkas A, Montaldi D (2014) Two separate, but interacting, neural systems for familiarity and novelty detection: a dual-route mechanism. Hippocampus 24:516-527. CrossRef Medline

Kelemen WL, Creeley CE (2003) State-dependent memory effects using caffeine and placebo do not extend to metamemory. J Gen Psychol 130:7086. CrossRef Medline

Manenti R, Brambilla M, Petesi M, Ferrari C, Cotelli M (2013) Enhancing verbal episodic memory in older and young subjects after non-invasive brain stimulation. Front Aging Neurosci 5:49. CrossRef Medline

Marshall L, Helgadóttir H, Mölle M, Born J (2006) Boosting slow oscillations during sleep potentiates memory. Nature 444:610-613. CrossRef Medline

Marshall L, Kirov R, Brade J, Mölle M, Born J (2011) Transcranial electrical currents to probe EEG brain rhythms and memory consolidation during sleep in humans. PloS One 6:e16905. CrossRef Medline

Murray LJ, Ranganath C (2007) The dorsolateral prefrontal cortex contributes to successful relational memory encoding. J Neurosci 27:5515-5522. CrossRef Medline

Neunuebel JP, Knierim JJ (2014) CA3 retrieves coherent representations from degraded input: direct evidence for CA3 pattern completion and dentate gyrus pattern separation. Neuron 81:416-427. CrossRef Medline

Norman KA, O’Reilly RC (2003) Modeling hippocampal and neocortical contributions to recognition memory: a complementary-learningsystems approach. Psychol Rev 110:611-646. CrossRef Medline

Nyhus E, Curran T (2010) Functional role of gamma and theta oscillations in episodic memory. Neurosci Biobehav Rev 34:1023-1035. CrossRef Medline

Oldfield RC (1971) The assessment and analysis of handedness: the Edinburgh inventory. Neuropsychologia 9:97-113. CrossRef Medline 
Osipova D, Takashima A, Oostenveld R, Fernández G, Maris E, Jensen O (2006) Theta and gamma oscillations predict encoding and retrieval of declarative memory. J Neurosci 26:7523-7531. CrossRef Medline

Petersen RC (1979) Scopolamine state-dependent memory processes in man. Psychopharmacology 64:309-314. CrossRef Medline

Polyn SM, Natu VS, Cohen JD, Norman KA (2005) Category-specific cortical activity precedes retrieval during memory search. Science 310:19631966. CrossRef Medline

Rolls ET (2016) Pattern separation, completion, and categorisation in the hippocampus and neocortex. Neurobiol Learn Mem 129:4-28. CrossRef Medline

Sandrini M, Brambilla M, Manenti R, Rosini S, Cohen LG, Cotelli M (2014) Noninvasive stimulation of prefrontal cortex strengthens existing episodic memories and reduces forgetting in the elderly. Front Aging Neurosci 6:289. CrossRef Medline

Sederberg PB, Kahana MJ, Howard MW, Donner EJ, Madsen JR (2003) Theta and gamma oscillations during encoding predict subsequent recall. J Neurosci 23:10809-10814. Medline

Sederberg PB, Schulze-Bonhage A, Madsen JR, Bromfield EB, Litt B, Brandt A, Kahana MJ (2007) Gamma oscillations distinguish true from false memories. Psychol Sci 18:927-932. CrossRef Medline

Sederberg PB, Schulze-Bonhage A, Madsen JR, Bromfield EB, McCarthy DC, Brandt A, Tully MS, Kahana MJ (2007) Hippocampal and neocortical gamma oscillations predict memory formation in humans. Cereb Cortex 17:1190-1196. CrossRef Medline

Simons JS, Spiers HJ (2003) Prefrontal and medial temporal lobe interactions in long-term memory. Nat Rev Neurosci 4:637-648. CrossRef Medline

Spiers HJ, Bendor D (2014) Enhance, delete, incept: manipulating hippocampus-dependent memories. Brain Res Bull 105:2-7. CrossRef Medline

Spiers HJ, de Cothi W, Bendor D (2017) Manipulating hippocampusdependent memories: to enhance, delete or incept? The hippocampus from cells to systems, pp 123-137. Cham Switzerland: Springer.

Staresina BP, Davachi L (2006) Differential encoding mechanisms for subsequent associative recognition and free recall. J Neurosci 26:9162-9172. CrossRef Medline

Staresina BP, Henson RN, Kriegeskorte N, Alink A (2012) Episodic reinstatement in the medial temporal lobe. J Neurosci 32:18150-18156. CrossRef Medline

Staresina BP, Michelmann S, Bonnefond M, Jensen O, Axmacher N, Fell J (2016) Hippocampal pattern completion is linked to gamma power increases and alpha power decreases during recollection. Elife 5:e17397. CrossRef Medline

Strüber D, Rach S, Trautmann-Lengsfeld SA, Engel AK, Herrmann CS (2014) Antiphasic $40 \mathrm{~Hz}$ oscillatory current stimulation affects bistable motion perception. Brain Topogr 27:158-171. CrossRef Medline

Suthana N, Haneef Z, Stern J, Mukamel R, Behnke E, Knowlton B, Fried I (2012) Memory enhancement and deep-brain stimulation of the entorhinal area. N Engl J Med 366:502-510. CrossRef Medline
Teyler TJ, Rudy JW (2007) The hippocampal indexing theory and episodic memory: updating the index. Hippocampus 17:1158-1169. CrossRef Medline

Thakral PP, Wang TH, Rugg MD (2015) Cortical reinstatement and the confidence and accuracy of source memory. Neuroimage 109:118-129. CrossRef Medline

Tompary A, Duncan K, Davachi L (2016) High-resolution investigation of memory-specific reinstatement in the hippocampus and perirhinal cortex. Hippocampus 26:995-1007. CrossRef Medline

Tulving E, Markowitsch HJ, Craik FE, Habib R, Houle S (1996) Novelty and familiarity activations in PET studies of memory encoding and retrieval. Cereb Cortex 6:71-79. CrossRef Medline

Turriziani P, Smirni D, Zappalà G, Mangano GR, Oliveri M, Cipolotti L (2012) Enhancing memory performance with rTMS in healthy subjects and individuals with mild cognitive impairment: the role of the right dorsolateral prefrontal cortex. Front Hum Neurosci 6:62. CrossRef Medline

Veniero D, Vossen A, Gross J, Thut G (2015) Lasting EEG/MEG aftereffects of rhythmic transcranial brain stimulation: level of control over oscillatory network activity. Front Cell Neurosci 9:477. CrossRef Medline

Viskontas IV, Knowlton BJ, Steinmetz PN, Fried I (2006) Differences in mnemonic processing by neurons in the human hippocampus and parahippocampal regions. J Cogn Neurosci 18:1654-1662. CrossRef Medline

Wang JX, Rogers LM, Gross EZ, Ryals AJ, Dokucu ME, Brandstatt KL, Hermiller MS, Voss JL (2014) Targeted enhancement of cortical-hippocampal brain networks and associative memory. Science 345:1054-1057. CrossRef Medline

Watrous AJ, Ekstrom AD (2014) The spectro-contextual encoding and retrieval theory of episodic memory. Front Hum Neurosci 8:75. CrossRef Medline

Watrous AJ, Tandon N, Conner CR, Pieters T, Ekstrom AD (2013) Frequency-specific network connectivity increases underlie accurate spatiotemporal memory retrieval. Nat Neurosci 16:349-356. CrossRef Medline

Watrous AJ, Fell J, Ekstrom AD, Axmacher N (2015) More than spikes: common oscillatory mechanisms for content specific neural representations during perception and memory. Curr Opin Neurobiol 31:33-39. CrossRef Medline

Wimber M, Maa $\beta$ A, Staudigl T, Richardson-Klavehn A, Hanslmayr S (2012) Rapid memory reactivation revealed by oscillatory entrainment. Curr Biol 22:1482-1486. CrossRef Medline

Yassa MA, Stark CE (2008) Multiple signals of recognition memory in the medial temporal lobe. Hippocampus 18:945-954. CrossRef Medline

Zaehle T, Rach S, Herrmann CS (2010) Transcranial alternating current stimulation enhances individual alpha activity in human EEG. PloS One 5:e13766. CrossRef Medline

Zwissler B, Sperber C, Aigeldinger S, Schindler S, Kissler J, Plewnia C (2014) Shaping memory accuracy by left prefrontal transcranial direct current stimulation. J Neurosci 34:4022-4026. CrossRef Medline 